\title{
The use of numerical modelling, slope monitoring and operational procedures to manage slope deformations at the Ranger 3 pit
}

\author{
D.R. Wines Itasca Australia Pty Ltd, Australia
}

I. Hulls Mining One Consultants, Australia

E. Woods Energy Resources of Australia Ltd, Australia

A. Creighton Rio Tinto, Australia

\begin{abstract}
Elevated slope movements were observed on the northeast wall of the Ranger 3 pit during excavation of the final pit shell. Both prism and radar monitoring indicated that the movement rate and magnitude were greater in this area when compared to surrounding areas, and periods of acceleration were evident. Several months after the initial onset of movement, tension cracks were observed behind the upper pit crest. At that stage, several benches were yet to be mined at the base of the wall, and concern existed regarding the safety of operations below the moving wall.

A calibrated three-dimensional numerical model was selected as the prime risk management strategy for mining the balance of the attainable ore in Pit 3. A detailed structural geological study was initially undertaken to provide reliable inputs for the modelling. The modelling was integrated into the overall risk management process, with the model being constantly updated based on the observed slope behaviour and the rock mass conditions being exposed at the toe of the slope. Ongoing and detailed calibration between the model behaviour and the comprehensive slope monitoring data was performed to provide a reliable understanding of the mechanism of movement, and to assess the likelihood of slope failure. Possible failure scenarios were also examined as a part of the risk management strategy, and strict operating procedures were implemented to minimise the risks associated with mining under an actively moving pit wall.
\end{abstract}

Although the modelling indicated that ongoing slope movements could be expected, slope failure was not predicted, provided that final pit excavation would be completed, as planned, prior to the upcoming wet season. In light of these modelling results, mining continued in Pit 3 based on the original mine plan, and final pit excavation was successfully completed in late 2012. Backfilling of the pit commenced soon after. After initial discovery of the tension cracks, some consideration had been given to incorporating a step-out in the lower part of the wall in an attempt to stabilise the observed movements. The successful risk management process, including detailed numerical modelling, comprehensive slope monitoring and strict operational procedures, allowed the original mine plan to be achieved, and therefore avoided the significant loss of ore associated with the proposed design change.

This paper summarises the numerical modelling methodology and results, the monitoring methods and data and the operational procedures that were used to successfully manage final pit completion.

1 Introduction

The Ranger Uranium Mine is located approximately $230 \mathrm{~km}$ east of Darwin in Australia's Northern Territory. The mine commenced operation in 1980 with the development of Pit 1, while Pit 3 commenced in 1997. The mine is operated by Energy Resources of Australia (ERA), which is a subsidiary of Rio Tinto. The mine experiences relatively high precipitation levels, with an annual rainfall of around $1,500 \mathrm{~mm}$. The wet season extends from October to April; however the majority of rainfall generally occurs between December and March. The Ranger mining lease is completely surrounded by the world heritage-listed Kakadu National 
Park, therefore the mine operates with a high degree of external visibility from regulatory and community stakeholders, and is particularly sensitive to environmental issues. The final Pit 3 excavation is around $1,150 \mathrm{~m}$ long, $800 \mathrm{~m}$ wide and up to $275 \mathrm{~m}$ deep. The final northeast wall is around $270 \mathrm{~m}$ high. As a part of ERA's ongoing rehabilitation programme, Pit 3 will be completely backfilled.

Comprehensive automated prism monitoring is utilised at the mine, and in late 2011, an obvious increase in movement rate was monitored on the northeast wall. The monitoring data indicated that movement rates are influenced by rainfall. In June 2012, tension cracks were discovered on the perimeter road behind the upper pit crest. At that stage, several benches were yet to be mined at the base of the northeast wall and the relatively low strength breccia material was to be exposed in the lower benches of the slope. All of these factors created significant concern regarding operational safety beneath the toe of the slope, and the ability to successfully achieve the planned final pit. Some consideration was given to incorporating a step-out in the lower part of the wall in an attempt to stabilise the movements.

A risk management strategy was adopted by the mine incorporating three-dimensional numerical modelling, comprehensive slope monitoring and strict operational procedures. This strategy was implemented in order to manage the risks associated with mining under an actively moving pit wall, and to reduce the need for any design changes and the associated loss of ore.

\section{$2 \quad$ Geotechnical setting and groundwater}

The main geological units encountered in Pit 3 are the hanging wall sequence (HWS), the upper mine sequence (UMS) and the lower mine sequence (LMS). The HWS is dominated by muscovite schists and amphibolites, the UMS consists of quartz-feldspar-biotite schists that have been altered to chlorite schist, while the LMS is comprised mainly of carbonate lithologies. The contacts between these units dip moderately towards the northeast. Both the HWS and the UMS units exhibit schistocity, and this fabric also dips moderately to the northeast. A brecciated zone of up to $40 \mathrm{~m}$ thickness exists between the UMS and LMS units, and this zone incorporates the Ranger 3 orebody. The condition of this breccia zone is highly variable. The depth of weathering in the vicinity of the northeast wall varies between around 15 and $50 \mathrm{~m}$ below ground surface.

Several medium and large scale faults have been interpreted in the study area. These faults are generally moderately to steeply-dipping. Many of the structures strike approximately east-west, although several major north-south faults as well as other orientations have also been identified. The distribution of the rock mass domains and faults is discussed and illustrated further in Section 5.2 below.

A creek with permanent flows exists behind the east wall of Pit 3 (Magella Creek), and it is understood that the phreatic surface is close to the ground surface at the creek location. Horizontal depressurisation holes of $150 \mathrm{~m}$ in length were drilled in the middle and upper benches of the wall, with $100 \mathrm{~m}$ long holes drilled in the lower sections down to around the $205 \mathrm{~m} \mathrm{RL}$. Based on piezometer monitoring and pit observations, it is understood that the phreatic surface is close behind the pit face below the level at which the horizontal holes were terminated, and approximately $50 \mathrm{~m}$ behind the wall above that level due to the effects of the depressurisation drilling.

\section{$3 \quad$ Monitoring observations and data assessment}

\subsection{Slope monitoring techniques}

Slope monitoring employed a three-tier approach following the discovery of pit crest tension cracks, as discussed below.

The prime monitoring tool was the GroundProbe Slope Stability Radar (SSR). The SSR units have gained wide acceptance in the hard rock mining industry since their introduction in 2002. The SSR scan region for the northeast wall was kept as tight as possible with scans typically being taken every ten to twelve minutes. 
The secondary monitoring tool was the mine wide prism monitoring system. This was the Softrock Solutions ATS system, and again this has gained industry wide acceptance since its initial site trials in 2000 . This has been in place for the life of Pit 3 at Ranger. Three ATS units were deployed, the third unit specifically set up to monitor the lower regions of the northeast wall, which is the subject of this paper.

The third tier was the manual check of installed crack monitoring pins and observational walk over of the pit crest and adjacent zones for several hundred metres beyond the pit crest, including the site access road.

\subsection{Observed slope movements}

\subsubsection{Slope stability radar}

Ad hoc SSR monitoring of the east wall had been undertaken on an irregular basis during the 2011 to 2012 wet season. A week long scan during March 2012 picked up an anomalous movement zone on the lower northeast wall. Inspection revealed a fault, later named lan's Fault, as the upper bound of this movement zone. From this time the single SSR unit was rotated between the northeast wall and the south wall until a second unit was sourced. This second unit commenced service in mid July 2012.

The daily reviews of the SSR data confirmed the initial trend of movement predominantly below lan's Fault. An example of the SSR data is provided in Figure 1.

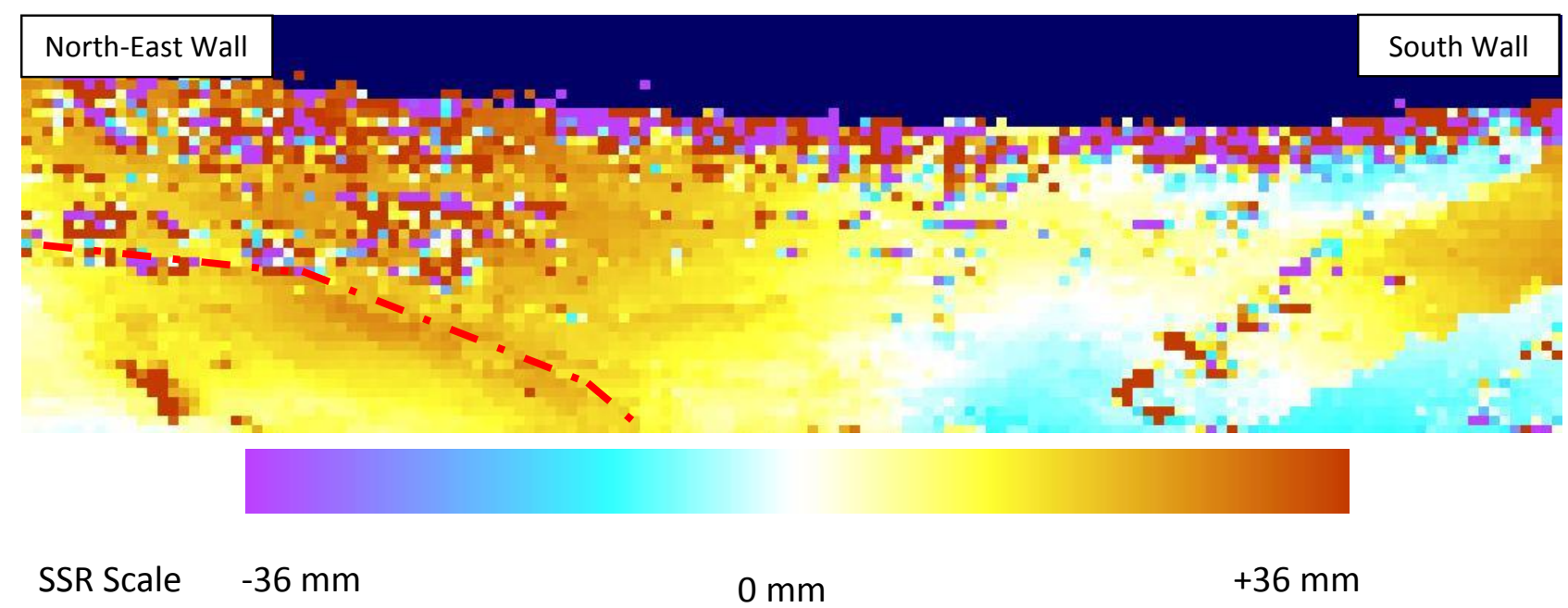

Figure 1 SSR data over 26 day's shows movement on lan's Fault (shown in red dashed line), a structure dipping $80^{\circ} / 65^{\circ}$ over the central portion. Movement has also been detected above this structure, visible between the scattered interference over this area of the plot

\subsubsection{ATS prism monitoring}

More than 90 prisms were progressively installed on the east and northeast wall during excavation. The automated prism monitoring data was alarmed at pre-set thresholds and data was reviewed on a daily basis.

A typical long term monitoring plot for Prism NE 65,031 is shown in Figure 2. This plot shows the northeast wall response to the onset of the 2011 to 2012 wet season, a minor slowing during March and April 2012 and then the response to mining and to the instability determined to be occurring on the northeast wall. 


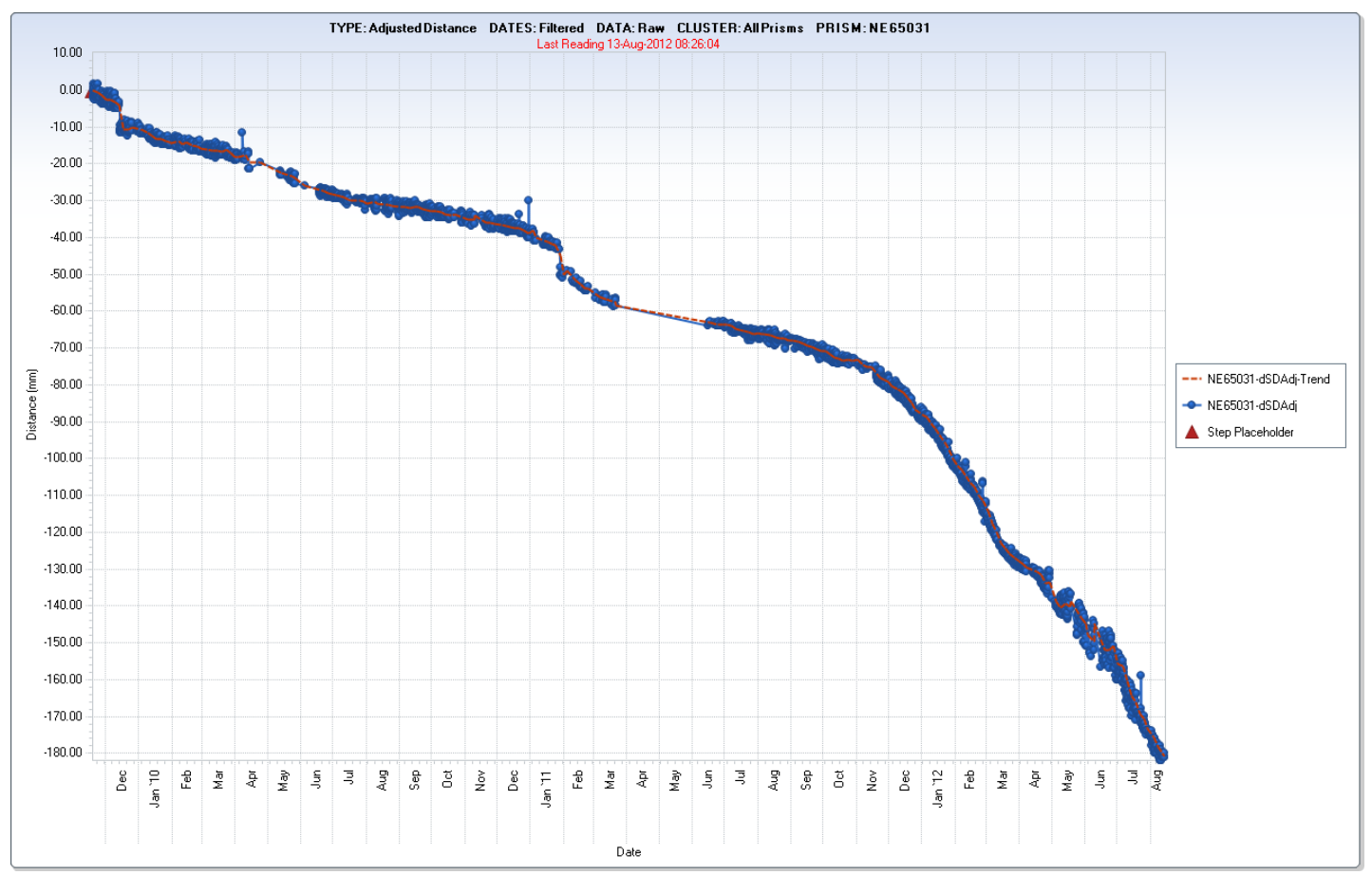

Figure 2 ATS prism data adjusted displacement plot for December 2009 to August 2012

A CAD plot view of northeast wall data is presented in Figure 3 below. This plot is for three months data from early July 2012 to early October 2012. The various colour vectors show displacement as per the legend, where the majority of movement on the upper wall is 50 to $75 \mathrm{~mm}$ over three months, with some peaks ranging from $75 \mathrm{~mm}$ up to $150 \mathrm{~mm}$ just below lan's Fault.

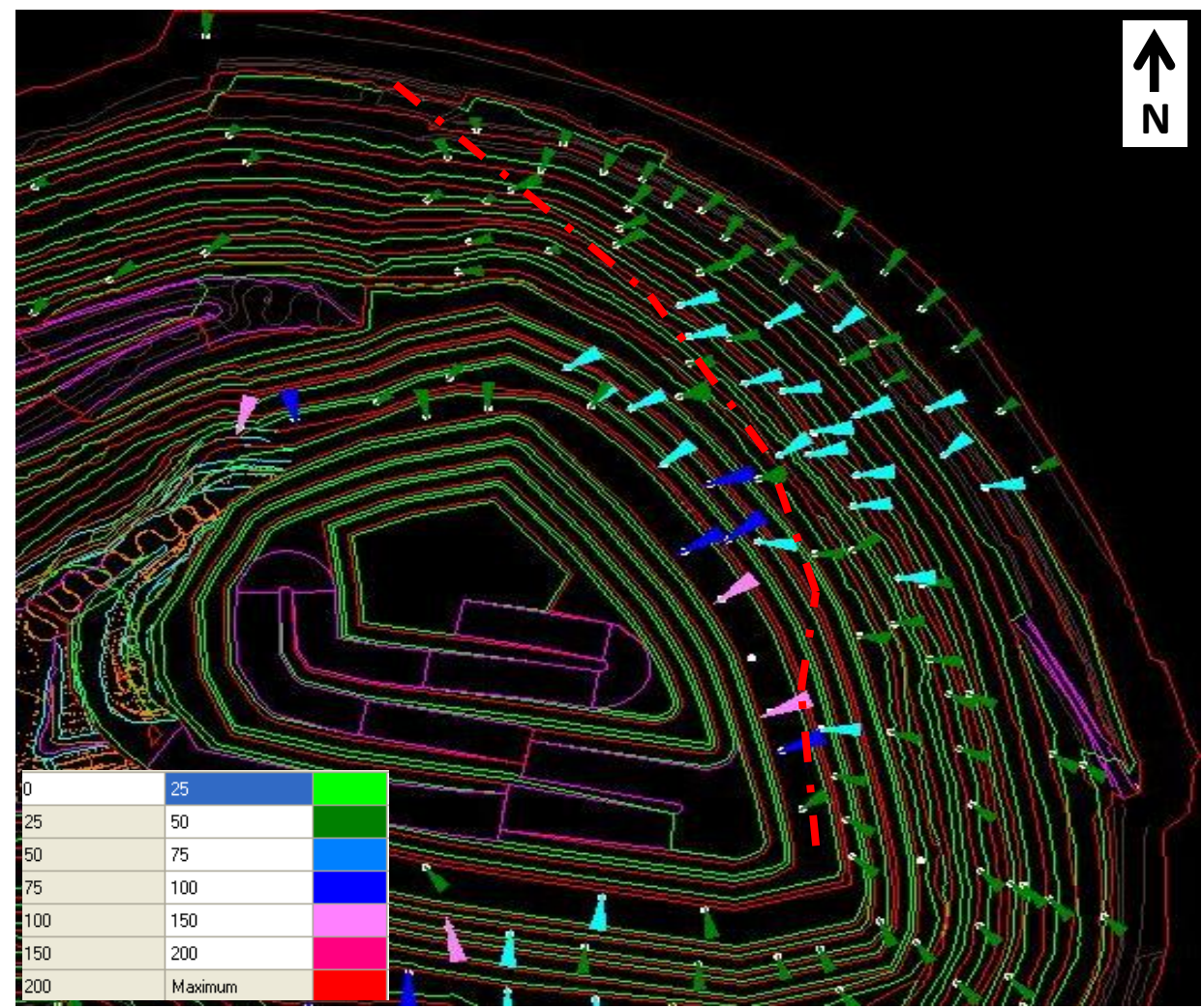

Figure 3 ATS data CAD plot for July to October 2012 with lan's Fault shown as red dashed line (approximate location) 


\subsection{Postulated pit wall movement mechanisms}

Discovery of tension cracks on the perimeter road and subsequently on the site access road were of concern to the geotechnical and management teams on site. These discoveries lead to the increased monitoring regimes discussed in previous sections above.

Based on the comprehensive data set available from the SSR monitoring, the ATS prism monitoring, the crack pins monitoring and the daily walkover observations, an in depth analysis of movement trends on the northeast wall was undertaken. The key points from this analysis were:

- The upper northeast wall was moving west and down.

- The zone immediately below lan's Fault was moving southwest and up.

- The balance of the zone below lan's Fault was moving southwest and down.

From this it was assessed that the northeast wall was undergoing an active/passive instability with the front block below lan's Fault moving out and down and the upper wall segment was dropping in behind this rotational movement below lan's Fault. This upper block movement was determined to be delineated by a north-south trending fault, a trace of which was noted in recent exploration drilling for the proposed underground exploration decline to the east of Pit 3. This delineation line/fault line was along the alignment of the tension cracks observed on the pit crest.

\section{$4 \quad$ Adopted risk management approach}

The key aims of the approach to mining the balance of Pit 3 were:

- To mine the maximum attainable ore from the base of Pit 3.

- To minimise the operational risk for those working below a moving slope.

The adopted risk management approach involved:

- The three-tiered monitoring strategy.

- Daily reports of monitoring observations.

- Additional characterisation work to improve knowledge of the geotechnical conditions in the moving area.

- Three-dimensional numerical modelling based on the updated geotechnical model to provide an improved understanding of the mechanism of movement and to help predict future slope behaviour.

- Weekly management meetings to review monitoring data and update mining and risk management strategies for the coming weeks, and to develop strategies to refine the modelling output.

A flow chart summarising the adopted approach is provided in Figure 4, while a more detailed discussion of each component is provided below. Particular attention is paid to the numerical modelling methodology and results. 


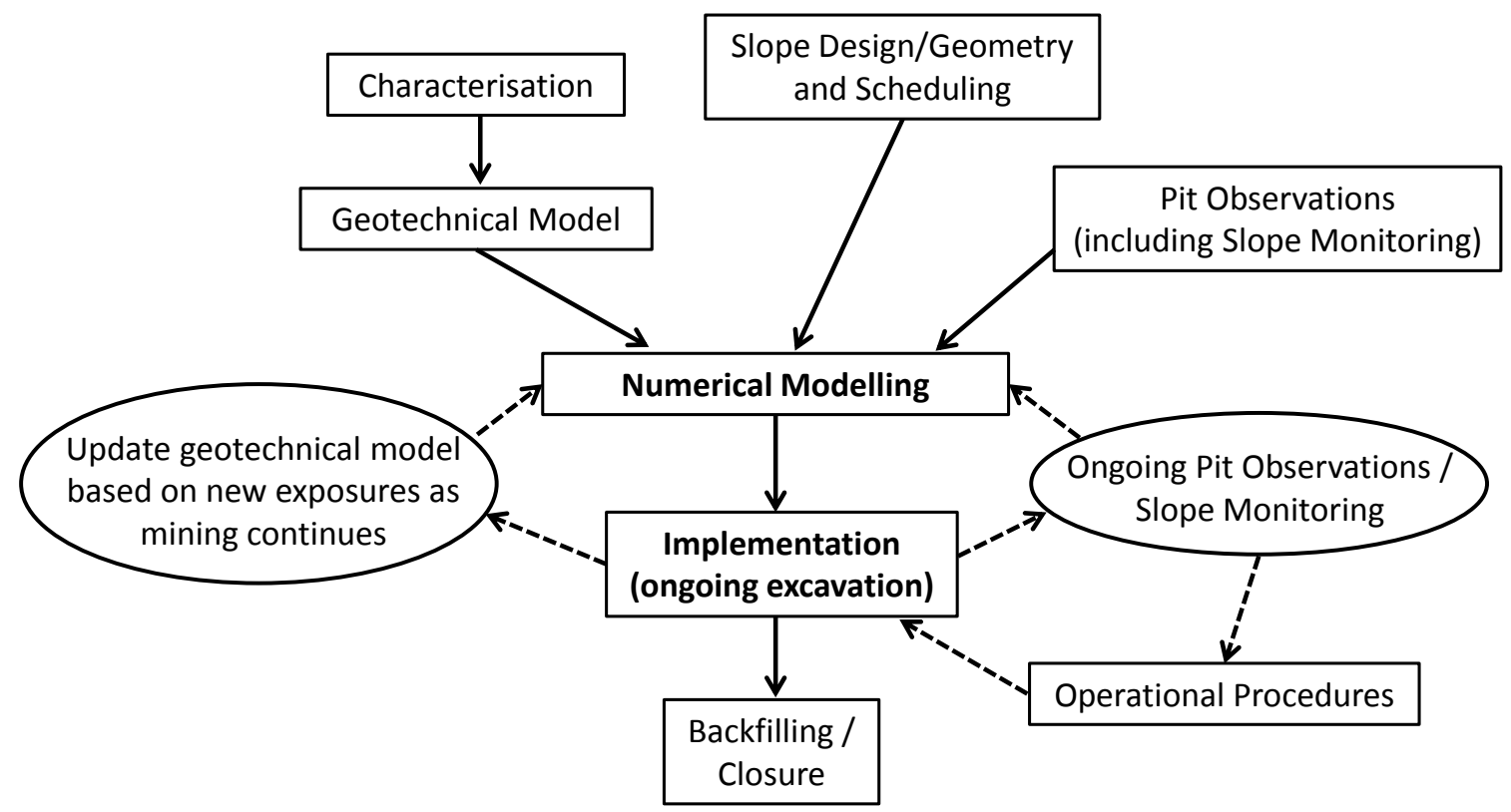

Figure 4 Flow chart summarising adopted risk management approach

\section{$5 \quad$ Numerical modelling methodology}

All of the relevant input variables for a numerical model representing the northeast wall are three-dimensional in nature (i.e. the pit geometry, the rock mass domains, the geological structures and the pore pressure distribution). Therefore, three-dimensional numerical modelling was selected to recreate the existing behaviour of the wall and to predict future stability. It was also probable that geological structures would play a significant role in stability, therefore the numerical analyses were performed using the three-dimensional distinct element code 3DEC (Itasca, 2010). A significant number of structures can be explicitly defined in a 3DEC model, and the material in between those structures (i.e. the rock masses) is represented as a mesh of finite difference elements.

\subsection{Geotechnical characterisation}

As a precursor to the study reported here, geotechnical characterisation was performed for the northeast wall based primarily on core logging, laboratory testing and face mapping data. After initial discovery of the pit crest tension cracks, an additional characterisation program was implemented. This included a detailed structural mapping program, which identified an additional 30 medium and large scale structures in the study area. Face mapping was also performed in the breccia material as this unit became exposed in the lower benches of the slope. The nature of this breccia material is highly variable depending on location, therefore characterisation from core logging and/or face mapping in other areas of the pit could not necessarily provide a reliable indication of the properties encountered at the base of the northeast wall.

\subsection{Model geometry, rock mass domains and geological structures}

A 3DEC model was constructed to include a large part of the Pit 3 east wall. An oblique view showing the exposed rock mass domains and geological structures in the model after excavation of the final pit is provided in Figure 5. Approximately 40 structures were explicitly-defined in the model, including all those structures identified in the latest characterisation program detailed above. Five rock mass domains were defined (weathered rock, schist, breccia, carbonate and E3 fault). The breccia zone is greater than $40 \mathrm{~m}$ thick in some areas. The north-south trending E3 fault was represented as a zone of around $15 \mathrm{~m}$ thickness. 


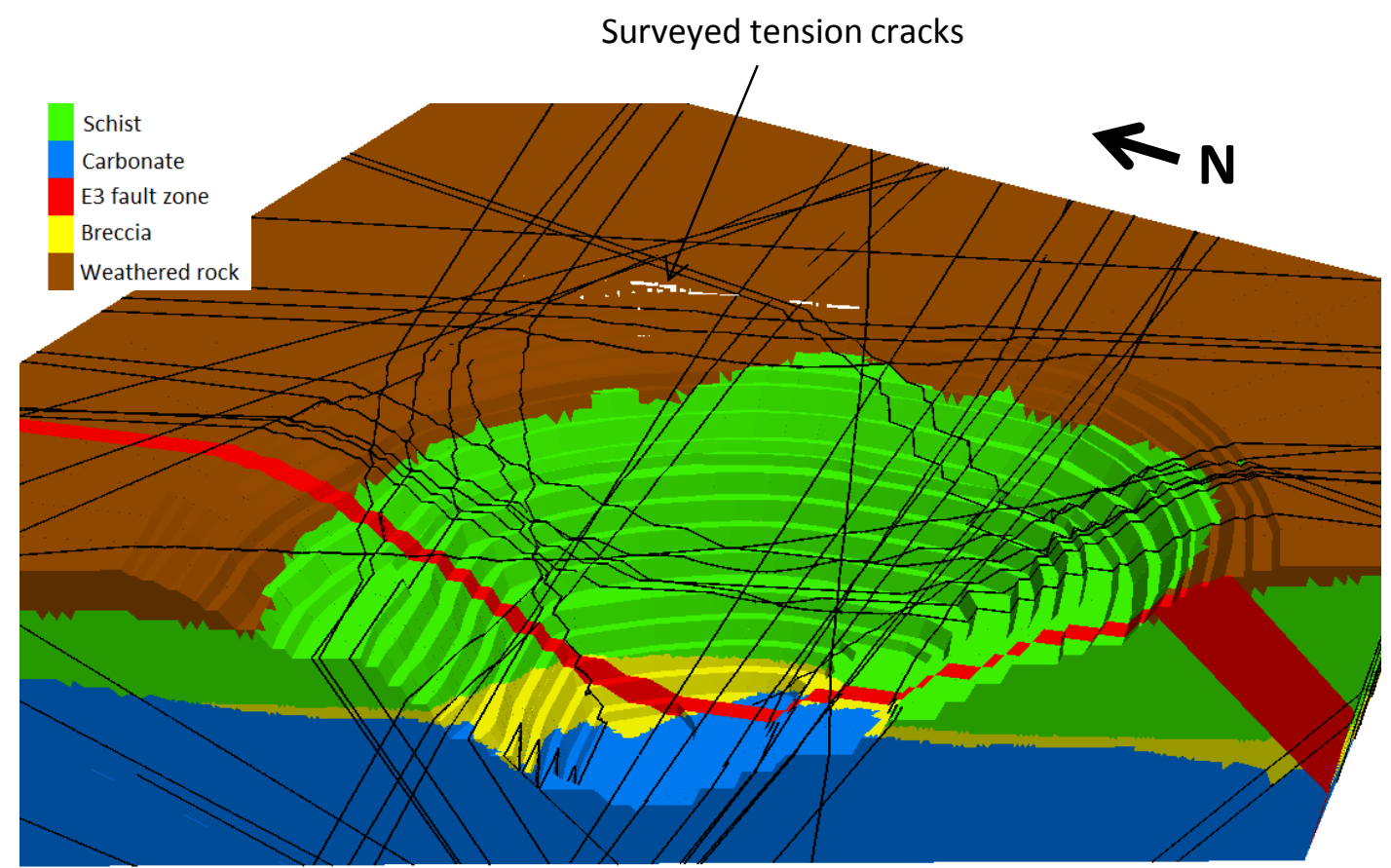

Figure 5 3DEC model geometry showing exposed rock mass domains and geological structures after excavation of the final pit

\subsection{Rock mass and fault properties}

The rock mass parameters adopted for the analyses are shown in Table 1 . The estimation of these parameters is discussed in detail below.

Table 1 Rock mass properties adopted for Ranger northeast wall numerical analyses

\begin{tabular}{|c|c|c|c|c|c|c|c|c|c|c|c|c|c|c|}
\hline \multirow[b]{2}{*}{$\begin{array}{l}\text { Rock Mass } \\
\text { Domain }\end{array}$} & \multirow[b]{2}{*}{$\begin{array}{c}v \\
\left(\mathrm{kN} / \mathrm{m}^{3}\right)\end{array}$} & \multirow[b]{2}{*}{$\begin{array}{c}\sigma_{c i} \\
(\mathrm{MPa})\end{array}$} & \multirow[b]{2}{*}{ GSI } & \multirow[b]{2}{*}{$m_{i}$} & \multirow[b]{2}{*}{$D$} & \multirow{2}{*}{$\begin{array}{c}\text { Max } \\
\sigma_{3} \\
(\mathrm{MPa})\end{array}$} & \multicolumn{2}{|c|}{ Segment 1} & \multicolumn{2}{|c|}{ Segment 2} & \multirow[b]{2}{*}{$\begin{array}{c}\sigma_{t m} \\
(\mathrm{kPa})\end{array}$} & \multirow[b]{2}{*}{$\begin{array}{l}\psi \\
\left(^{\circ}\right)\end{array}$} & \multirow[b]{2}{*}{$\begin{array}{c}E_{r m} \\
(\mathrm{GPa})\end{array}$} & \multirow[b]{2}{*}{$v_{r m}$} \\
\hline & & & & & & & $\begin{array}{c}c \\
(\mathrm{kPa})\end{array}$ & $\begin{array}{c}\phi \\
\left({ }^{\circ}\right)\end{array}$ & $\begin{array}{c}c \\
(\mathrm{kPa})\end{array}$ & $\begin{array}{c}\phi \\
\left({ }^{\circ}\right)\end{array}$ & & & & \\
\hline $\begin{array}{l}\text { Weathered } \\
\text { rock }\end{array}$ & 24 & - & - & - & - & - & 23 & 38 & - & - & 6 & 5 & 0.54 & 0.28 \\
\hline $\begin{array}{l}\text { Muscovite } \\
\text { Schist }\end{array}$ & 27 & 70 & 55 & 10 & 0.7 & 1.5 & 504 & 51 & 970 & 40 & 122 & 10 & 5.00 & 0.24 \\
\hline Breccia & 27 & - & - & - & - & - & 300 & 40 & - & - & 20 & 5 & 2.50 & 0.27 \\
\hline $\begin{array}{l}\text { E3 fault } \\
\text { zone }\end{array}$ & 27 & - & - & - & - & - & 300 & 40 & - & - & 20 & 5 & 2.50 & 0.27 \\
\hline Carbonate & 27 & 100 & 65 & 10 & 0.7 & 1.5 & 1,385 & 52 & 1,885 & 46 & 429 & 10 & 23.08 & 0.22 \\
\hline $\begin{aligned} \gamma & =\text { unit we } \\
\sigma_{c i} & =\text { uniaxia } \\
G S I & =\text { Geolog } \\
m_{i} & =\text { Hoek }- \\
D & =\text { Hoek } \\
\sigma_{3} & =\text { minor }\end{aligned}$ & $\begin{array}{l}\text { compressive } \\
\text { cal Strength I } \\
\text { rown materia } \\
\text { rown disturb } \\
\text { rincipal stres }\end{array}$ & $\begin{array}{l}\text { strength c } \\
\text { ndex } \\
\text { al constant } \\
\text { ance facto } \\
\text { s }\end{array}$ & fo & ck & & $\begin{array}{l}c= \\
\phi= \\
\sigma_{t m}= \\
\psi= \\
E_{r m}= \\
v_{r m}=\end{array}$ & $\begin{array}{l}\text { ock mass d } \\
\text { 'oung's mo } \\
\text { oisson's ra }\end{array}$ & lulus $\mathrm{f}$ & $\begin{array}{l}\text { ingle } \\
\text { trength } \\
\text { angle } \\
\text { or the rock } \\
\text { he rock ma }\end{array}$ & & & & & \\
\hline
\end{tabular}

The weathered rock, breccia and E3 fault zone were represented in the model using a linear elastic perfectly plastic Mohr-Coulomb model with tension strength cut-off. This was considered reasonable, because these relatively low strength materials would be expected to exhibit a reasonably ductile behaviour during and after failure. 
The shear strength (cohesion and friction angle) and tensile strength for the schist and carbonate domains were estimated based on the Hoek-Brown failure criterion as described by Hoek et al. (2002). The shear strength for these materials was estimated by fitting a bilinear Mohr-Coulomb envelope to the non-linear Hoek-Brown curve. This allows the cohesion and friction angle to be determined for two intervals of confining stress (referred to as Segment 1 and Segment 2 in Table 1). Strain-softening was also assigned to these materials, whereby the adopted shear and tensile strength can reduce based on the amount of plastic strain that occurs in each model zone.

The schist domain exhibits a fabric (or schistosity), and it is likely that this schistosity creates some strength anisotropy. This is evident when viewing the UCS test results for the schist, which indicate a change in rock strength with loading direction. This fabric was represented in the schist domain using the ubiquitous joint model in 3DEC, which provides an orientation of weakness in a Mohr-Coulomb material. The ubiquitous joint properties were verified using numerical laboratory tests to ensure that a reasonable rock mass response was achieved in all loading directions.

Initially, Young's modulus for the rock mass was estimated based on the GSI using the simplified equation provided by Hoek and Diederichs (2006). The properties used to represent the structures that are explicitly defined in the model are shown in Table 2. Fault characterisation indicated that these adopted values were reasonable.

Table 2 Fault properties adopted for Ranger northeast wall numerical analyses

\begin{tabular}{|c|c|c|c|c|c|c|}
\hline & $k_{n}(\mathrm{GPa} / \mathrm{m})$ & $k_{s}(\mathrm{GPa} / \mathrm{m})$ & $C(\mathrm{kPa})$ & $\phi\left(^{\circ}\right)$ & $\sigma_{t}(\mathrm{kPa})$ & $\boldsymbol{\psi}\left({ }^{\circ}\right)$ \\
\hline & 10 & 1 & 25 & 28 & 0 & 0 \\
\hline $\begin{array}{l}k_{n} \\
k_{s}\end{array}$ & $\begin{array}{l}=\text { fault normal stiffness } \\
=\text { fault shear stiffness } \\
=\text { fault cohesion }\end{array}$ & $\begin{array}{l}\phi=\text { fau } \\
\sigma_{t}=\text { fau } \\
\psi=\text { fau }\end{array}$ & $\begin{array}{l}\text { ction angle } \\
\text { nsile strength } \\
\text { ation angle }\end{array}$ & & & \\
\hline
\end{tabular}

Note that the properties shown in Tables 1 and 2 are those values that were adopted for the final model. As part of the ongoing calibration process, various input parameters were altered in order to obtain a reasonable correlation between the modelling results and the observed slope behaviour. This calibration process is discussed further in Section 6 below.

\subsection{Groundwater, in situ stresses and modelling sequence}

A three-dimensional phreatic surface was constructed for modelling purposes, and hydrostatic conditions were assumed below that surface. The location of the surface was based on pit observations and monitoring data. Based on available information, it was assumed that the vertical in situ stress is lithostatic (based on the weight of the rock above) and the horizontal to vertical stress ratio is 1.5. Pit excavation was simulated in the model from top to bottom on a bench-by-bench basis. Excavation of the as-built pit was initially simulated, followed by excavation of the final pit shell.

\section{Model calibration}

Numerous model runs were initially performed to provide a reasonable calibration between pit observations and the monitoring data. Model inputs that were altered to provide this calibration included the continuity of the faults, the shear strength properties assigned to the faults, the rock mass modulus assigned to all units and the shear strength assigned to the breccia material and the E3 fault zone.

An oblique view showing cumulative displacement contours (in metres) produced by the model after excavation of the as-built pit (as of October 2012) is provided in Figure 6. A cross section view through the moving area is also provided in the figure. The displacements shown on these plots are the cumulative displacements that have occurred in the model since the initial commencement of mining. 


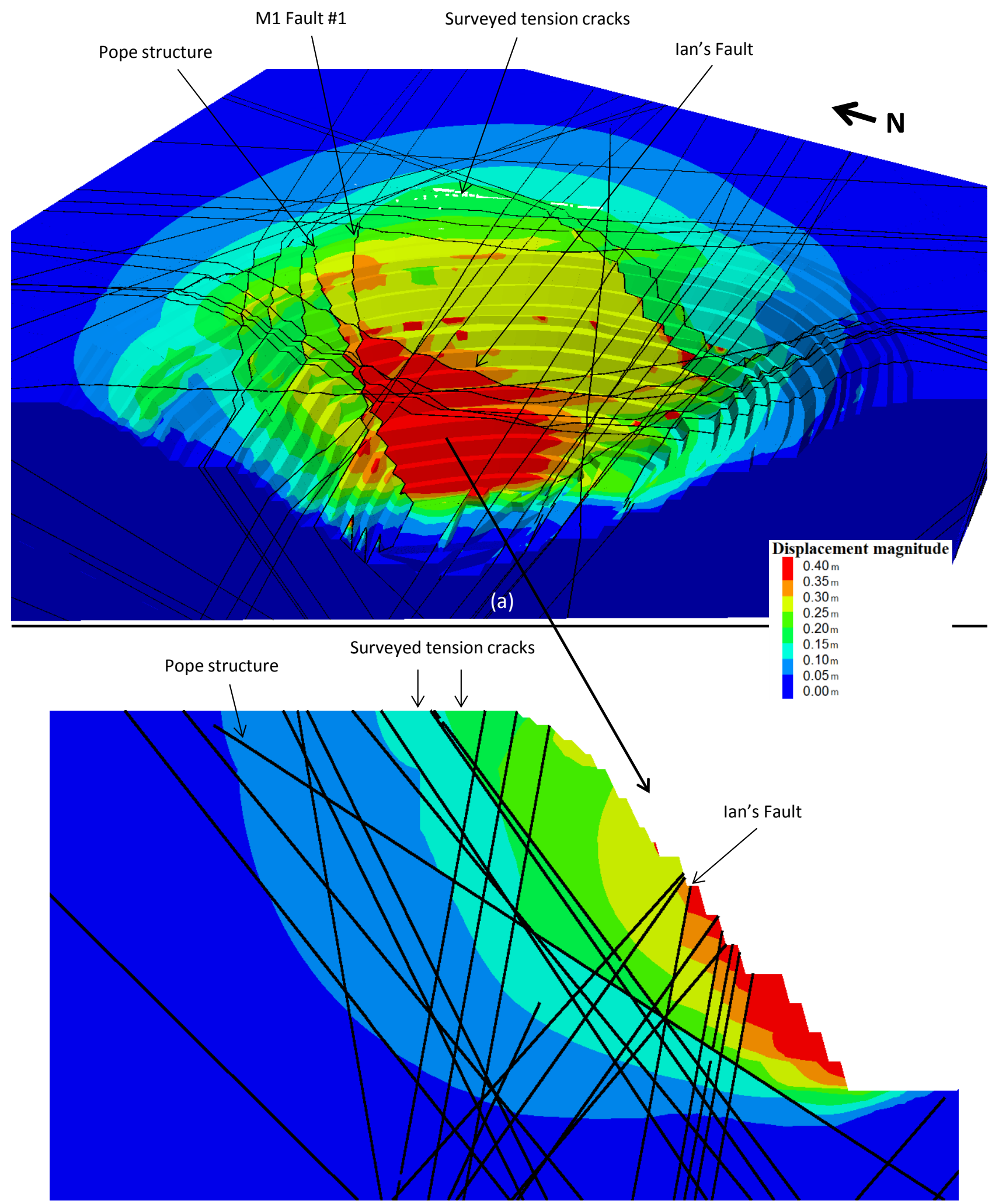

(b)

Figure 6 Cumulative displacement contours in metres after excavation of the as-built (October 2012) pit, oblique view (a); and cross section view (b)

It is seen that localised displacements occurred in the model adjacent to the steeply-dipping 'Pope' structure and below the steeply-dipping lan's Fault, both of which are labelled on the figures. This was consistent with pit observations and monitoring data at the time. SSR radar monitoring had shown elevated 
displacements in this area, and lan's Fault had shown some signs of disturbance in the pit wall. Despite these elevated displacements, low model velocities and other indicators showed that progressive slope failure did not occur at the as-built excavation stage.

Monitoring points were included in the model at the location of several of the existing prisms. Charts are provided in Figure 7 showing monitored and modelled displacements over time for six selected prisms spread throughout the moving area. It is seen that a very good correlation was obtained at this stage of the modelling process. The northing, easting and RL components of movement were also studied, as were movement vectors over selected excavation periods.
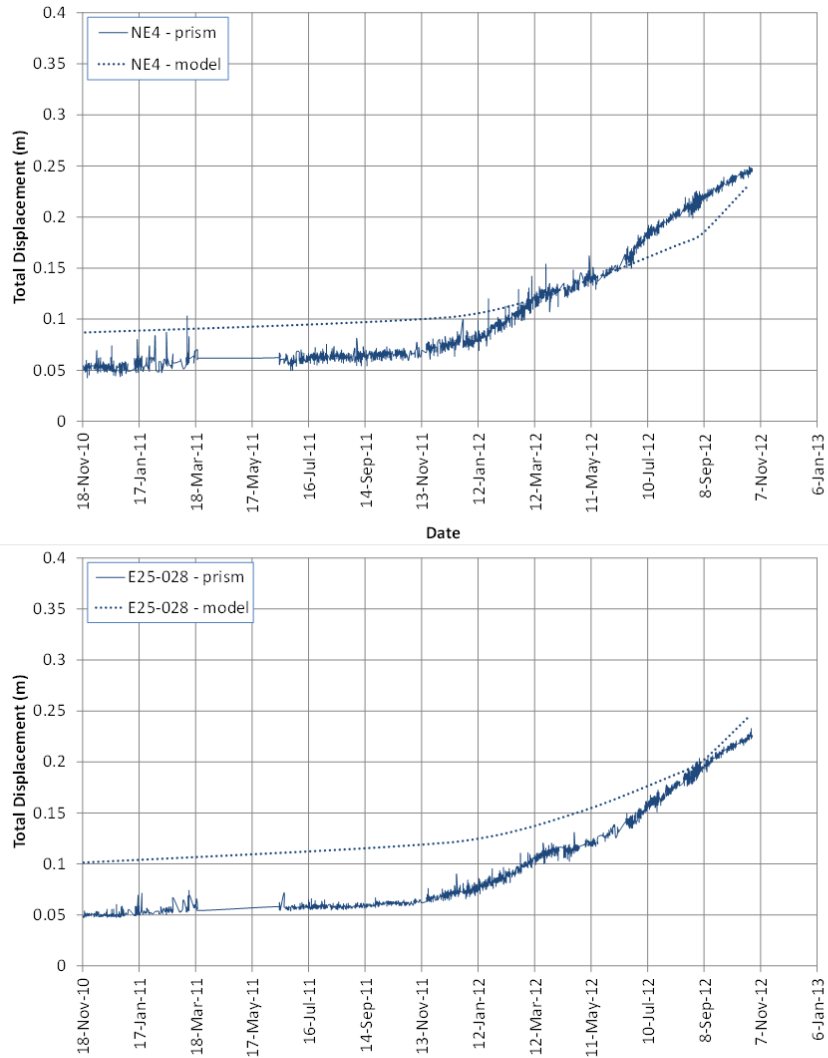

Dat

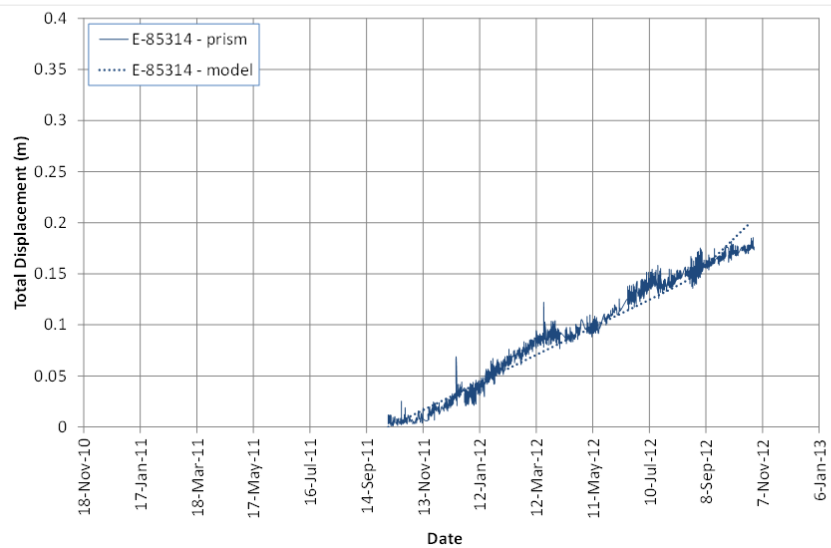

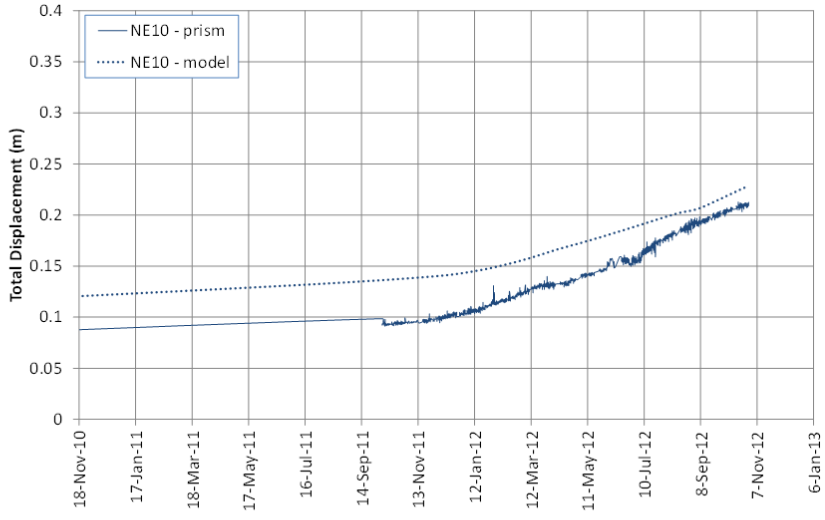

Date

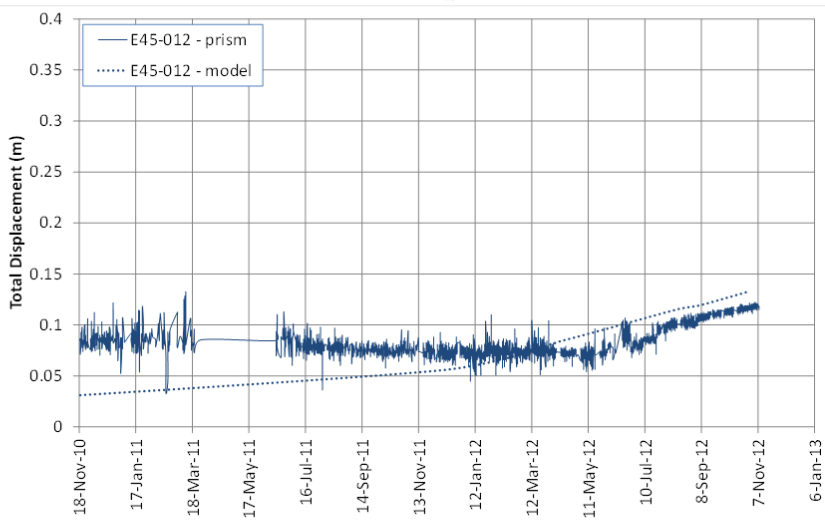

Date

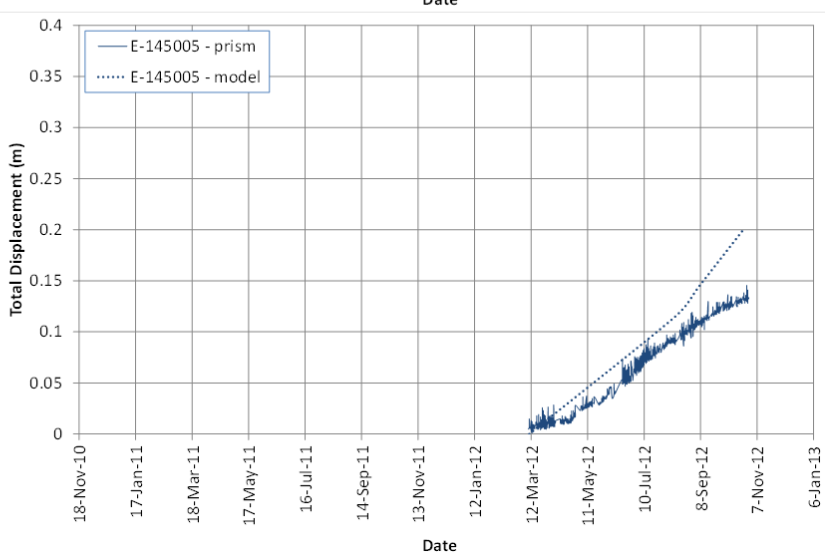

Figure 7 Charts showing modelled and monitored displacements over time for six selected monitoring points, after excavation of as-built pit (as of October 2012)

As discussed, the model calibration process was ongoing as additional monitoring and characterisation data became available. As the relatively low strength breccia material was exposed in the lower benches of the wall, mapping indicated that this material was stronger than initially expected at the base of the moving zone. Increasing the properties assigned to this material provided the final calibration detailed above. 


\subsection{Discussion on model calibration}

It is interesting to note that on several occasions prior to the final calibration, the model was thought to be providing a reasonable calibration to the monitoring data based on slightly different input parameters to those detailed above. This highlights that a favourable comparison between modelled and monitored displacements does not necessarily mean that the adopted input parameters are truly representative of the true conditions in the pit wall.

Based on the authors' experience, it is also noted that:

- In many cases, particularly for stable pit slopes, close correlation between monitored and modelled displacements may indicate that the adopted elastic properties are accurate, but do not necessarily mean that the adopted strength properties are accurate. These strength properties are typically the most important material parameter in a slope stability analysis.

- There may be more than one combination of inputs (including material properties, in situ stresses and groundwater pressures) that provide a reasonable calibration. Of course, only one of those sets of inputs can be truly representative of the actual conditions in the pit wall.

- The input parameters that provide a reasonable calibration will most likely differ depending on the adopted analysis technique (i.e. two-dimensional versus three-dimensional, limit equilibrium versus numerical analysis).

\section{$7 \quad$ Predicted final pit stability}

Cumulative displacement contours and numerical velocity contours produced by the model after excavation of the final pit are provided in Figure 8. Similarly to the as-built pit, elevated displacements had occurred in the model adjacent to the steeply-dipping Pope structure and below lan's Fault. Despite these elevated displacements, the low velocities indicated that progressive failure was not predicted after excavation of the final pit, based on dry season conditions.

A chart showing modelled and monitored displacements for the six selected prisms, shown previously in Figure 7, is provided in Figure 9. This is the same data set as shown in Figure 7, with the modelled data continued to complete pit excavation. It is seen that, as of October 2012, no significant displacements or acceleration were expected during future excavation. This was consistent with other model outputs such as displacement contours, rock mass damage, etc., all of which indicated that no significant changes in slope behaviour were expected during excavation of the remaining lower benches. This provided confidence to the mine management team that the final pit could be successfully achieved without any alterations to the pit design. All previous model predictions, based on superseded calibrations, also predicted that, despite the ongoing elevated displacements being monitored in the northeast wall, failure would not occur in the final pit under dry season conditions.

Shear strength reduction analyses were also performed, and these indicated that that the Factor of Safety for the final wall was at least 1.2 for dry season conditions. Additional sensitivity studies were performed with various alternative phreatic surfaces and pore pressure distributions to assess the potential for rainfall to adversely affect stability. As expected, the additional analyses predicted a less stable situation with higher pore pressures, however the analyses did indicate that relatively short periods of rainfall would not cause slope failure. Other analyses were also performed for an alternative pit design (with a step-out in the lower part of the wall) and to assess the effects of future backfilling on wall stability, however these are not discussed in detail here. 


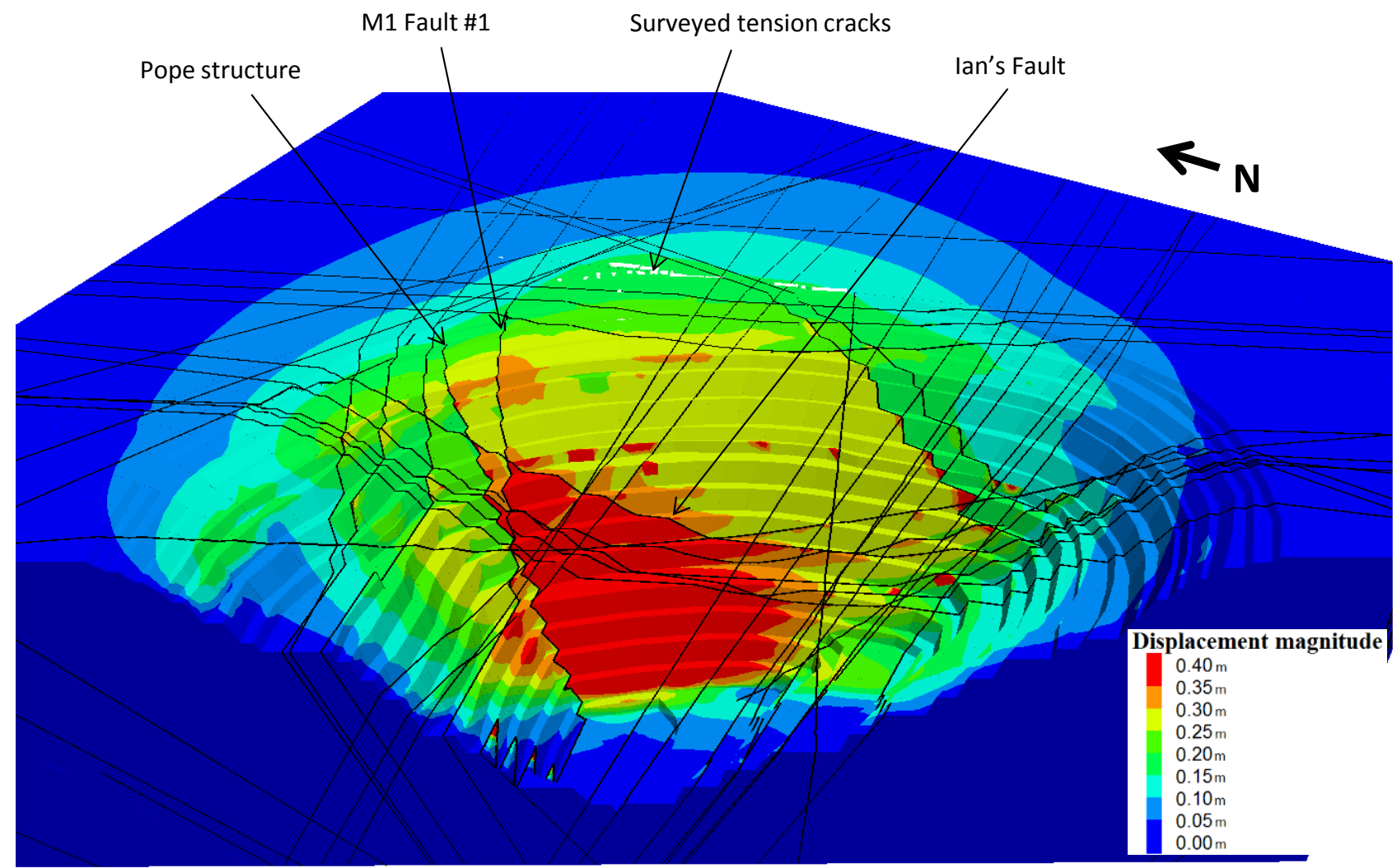

(a)

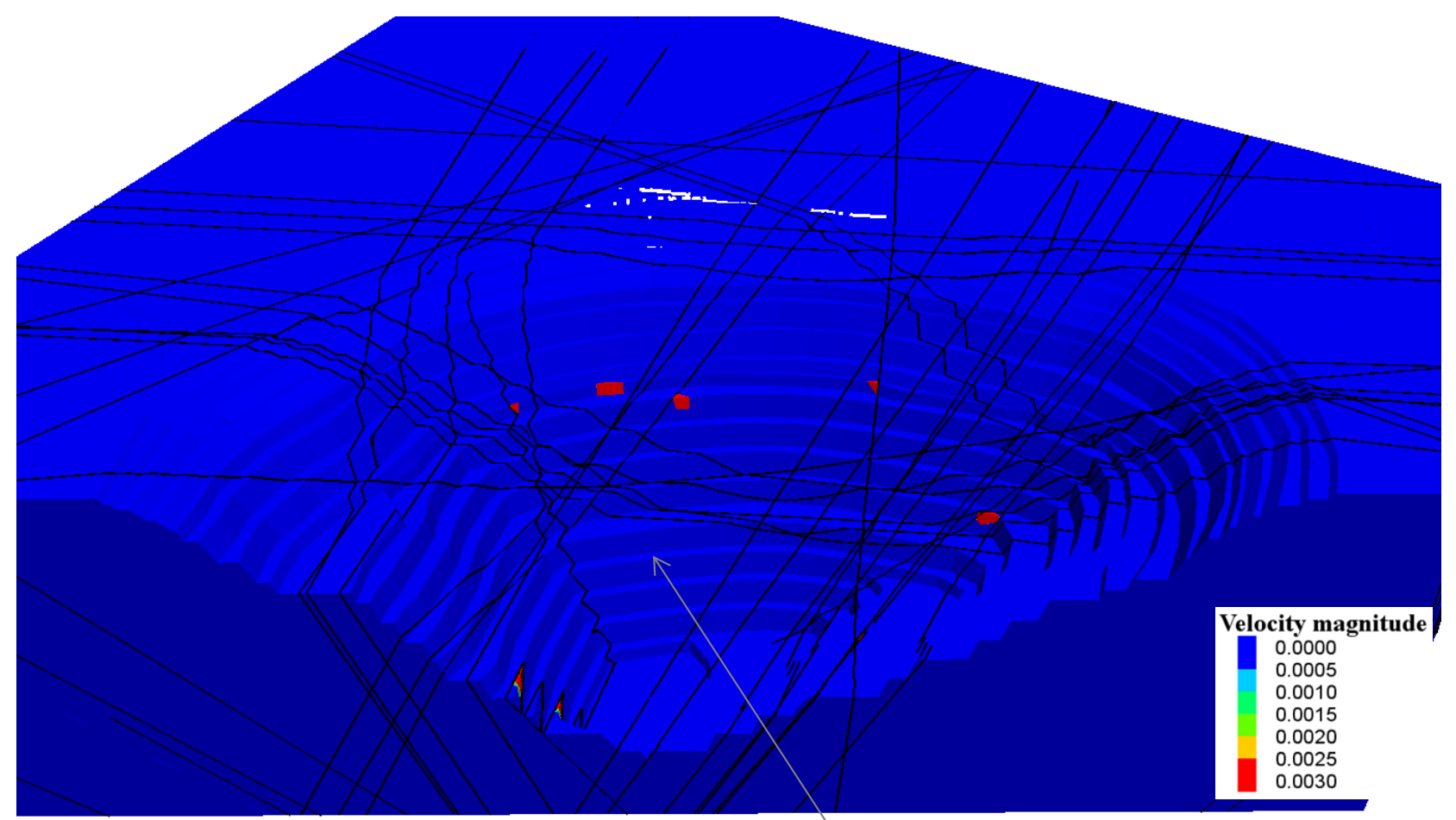

Low velocities indicate that progressive failure is not predicted by the model.

(b)

Figure 8 Cumulative displacement contours in metres (a); and velocity contours in metres per model step (b) after excavation of final pit 


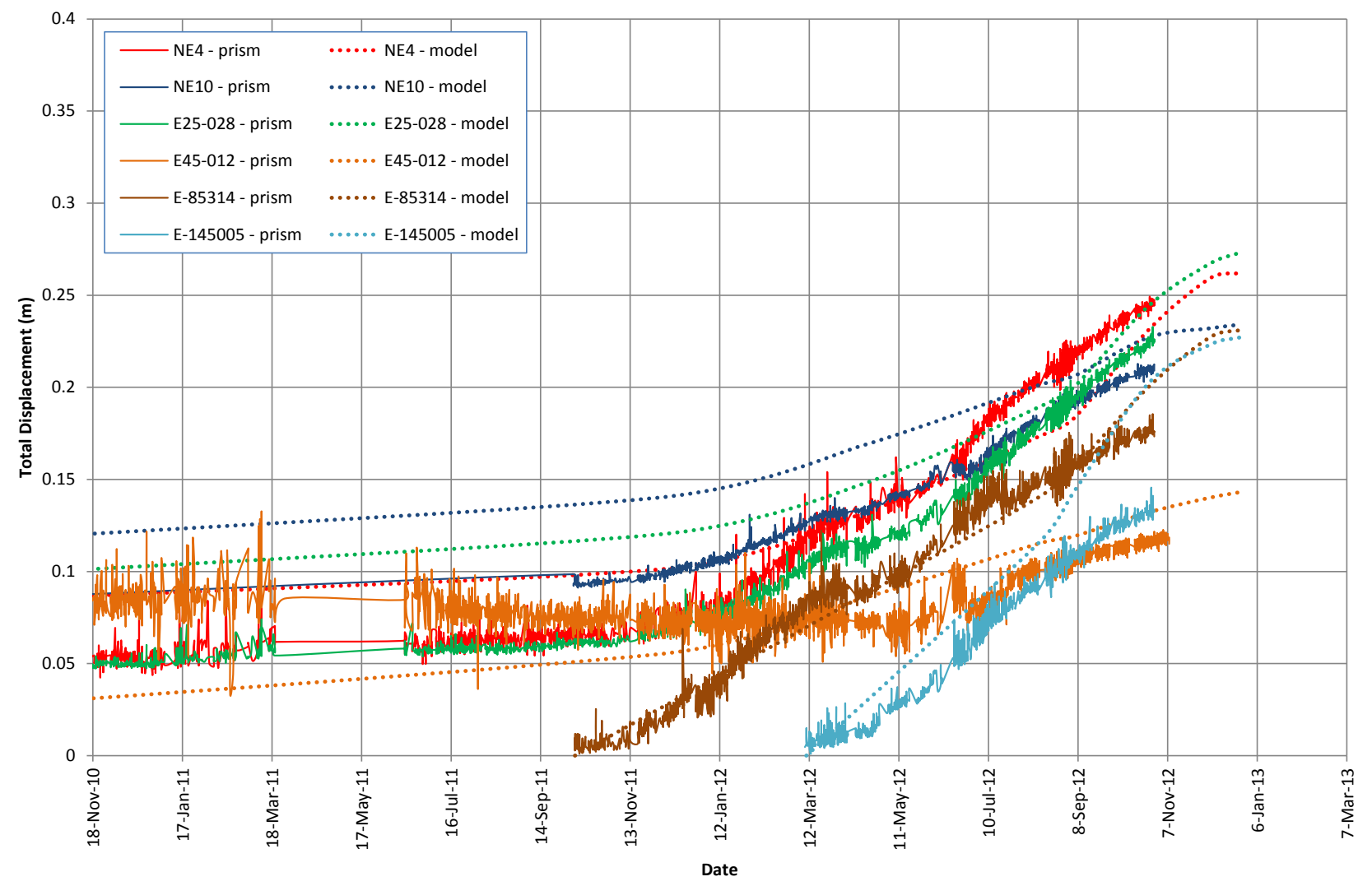

Figure 9 Chart showing monitored displacements to the as-built stage and modelled displacements to completion of mining for six selected monitoring points

\section{Summary of risk management outcomes}

The adopted risk management approach of the three-tiered monitoring and inspection program, geotechnical characterisation, numerical modelling and increased communication levels on site led to a complete review of all operational procedures pertaining to geotechnical risk management. The basis for the procedural review was the results of the numerical modelling, the subject of this paper, along with the development of an updated Trigger Action Response Plan (TARP) for Pit 3. The key points of the TARP were:

- Response to observations and monitoring.

- Response to the effects of blasting.

- Onset of the wet season.

These points are discussed respectively below.

Pit evacuation procedures were implemented in response to instability observations and to the alarms set on the SSR radar and ATS prism monitoring systems. SSR alarm thresholds were set at low levels, typically $4 \mathrm{~mm}$ for a geotechnical alarm and $6 \mathrm{~mm}$ for a red alarm that triggered the pit evacuation procedure. Site geotechnical staff were on call 24 hours per day to respond to monitoring alarms and also to any instability observations by pit operational staff.

Geotechnical staff monitored the effects of pit blasts on wall stability. As a minimum, each blast was monitored live on the SSR output for several scans immediately post blast and visual monitoring of blasts was undertaken where it was deemed a blast, such as a trim shot immediately below the northeast wall, may have prompted pit wall instability.

A key point from the numerical modelling was that the wet season onset could jeopardise the stability of the northeast wall. In response to this, the mining schedule was adjusted to mine to the final pit depth as 
quickly as possible while at the same time maintaining the strict risk management strategies that had been implemented.

This adopted risk management strategy was successful and the last truck load was loaded mid November 2012, prior to the onset of heavy rainfall events. Backfilling of the pit commenced immediately after pit completion.

\section{Conclusions}

The final pit was successfully excavated without slope failure, which is consistent with the predictions provided by the three-dimensional numerical modelling. Successful recreation of the movement mechanism in the model, and the accurate model predictions, were enabled by the comprehensive characterisation program and the ongoing calibration process. The model could not have recreated the structurally-controlled movement mechanism without the explicit representation of faults. The three-dimensional modelling methodology also assisted in recreating the mechanism, because all of the relevant geometric input parameters are fundamentally three-dimensional in nature. The ongoing calibration process was critical because the relatively low strength breccia material that was encountered in the lower benches of the wall is highly variable based on location, and therefore very difficult to accurately characterise using limited borehole information and mapping from other areas of the pit. When this material became exposed at the toe of the wall allowing detailed mapping, its condition was found to be better than expected.

The overall risk management process associated with the moving wall was a success due to the teamwork and commitment of several contributors including ERA / Rio Tinto engineers and various consultants. The comprehensive management process included regular and ongoing communication which provided confidence to key stakeholders including mine management and the operations team.

The successful completion of the preferred Pit 3 design indicates that, although the monitoring of pit wall displacements and acceleration and the formation of tension cracks in a pit wall can provide an early indication of potential instability, they do not necessarily indicate that slope failure is imminent, or that slope failure will occur.

\section{Acknowledgement}

The authors thank Energy Resources Australia Ltd for permission to publish this paper.

\section{References}

Hoek, E., Carranza-Torres, C. and Corkum, B. (2002) Hoek-Brown Failure Criterion - 2002 edition, in Proceedings 5th North American Rock Mechanics Symposium and 17th Tunnelling Association of Canada Conference (NARMS-TAC, 2002), R. Hammah, W. Bawden, J. Curran and M. Telesnicki (eds), 7-10 July 2002, Toronto, Canada, University of Toronto Press, Toronto, Vol. 1, pp. 267-273.

Hoek, E. and Diederichs, M.S. (2006) Empirical estimation of rock mass modulus, International Journal of Rock Mechanics and Mining Sciences, Elsevier, Vol. 43, pp. 203-215.

Itasca (2010) 3DEC Three-Dimensional Distinct Element Code, Version 4.2, Itasca Consulting Group, http://itascacg.com/software/ 3dec. 